\title{
Practice
}

\section{Pregnancy and congenital heart disease}

\author{
Anselm Uebing, Philip J Steer, Steve M Yentis, Michael A Gatzoulis
}

Congenital heart disease occurs in $0.8 \%$ of newborn infants around the world. Advances in medical and surgical treatments over the past decades has led to more than $85 \%$ of these infants surviving to adulthood. ${ }^{12}$ Most interventions, however, have not been curative and about half of adults with congenital heart disease face the prospect of further surgery, arrhythmia, heart failure, and-if managed inappropriately-premature death. The burden of pregnancy represents a new challenge in women with congenital heart disease.

In the United Kingdom about 250000 adults have congenital heart disease (also known as "grown up congenital heart disease (GUCH)" patients), and this number is growing. ${ }^{3}$ Half of these patients are women, most of reproductive age. After suicide, cardiac disease is now the leading cause of maternal death in the UK, with most of these casualties having had congenital heart disease. ${ }^{4}$ The medical profession should therefore be aware of the risks that women with congenital heart disease face during pregnancy so that they can be given adequate preconception counselling and optimal care during pregnancy, delivery, and the postpartum period. ${ }^{5-7}$

\section{Preconception counselling}

Discussions about future pregnancies, family planning, and contraception should begin in adolescence to prevent accidental and potentially dangerous pregnancies in women with congenital heart disease. The impact of heart disease on childbearing potential needs to be explained clearly and sympathetically. Counselling has to address how pregnancy may affect not just the mother but also the fetus and the rest of the family (box 1). This allows women to make an informed choice whether they wish to accept the risks associated with pregnancy. The counselling should ideally be provided in a joint clinic by an obstetrician with expertise in heart disease and a cardiologist with special training in adult congenital heart disease.

\section{The risk for the mother}

The risk for pregnant women with congenital heart disease of having adverse cardiovascular events-such as symptomatic arrhythmia, stroke, pulmonary oedema, overt heart failure, or death-is determined by the ability of their cardiovascular system to adapt to the physiological changes of pregnancy (fig 1). Different congenital conditions carry specific risks based on their morphological features, previous operations, and

\section{Summary points}

Cardiac disease is a leading cause of maternal death in the UK (second only to suicide), and most affected women have congenital heart disease. The number of such cardiac patients at risk is expected to grow

Timely pre-pregnancy counselling should be offered to all women with congenital heart disease to prevent avoidable pregnancy-related risks and crisis management and allow patients to plan their lives

Adequate care during pregnancy, delivery, and the postpartum period requires a multidisciplinary team approach with cardiologists, obstetricians, and anaesthetists

Successful pregnancy is feasible for most women with congenital heart disease at relatively low risk when appropriate counselling and optimal care are provided

current haemodynamic status (see table 1). One cannot overemphasise the need for thorough assessment of patients with congenital heart disease before pregnancy: this forms the basis for risk stratification, advice, and decision making (box 2).

\section{The risk to the fetus}

Overall, there is a higher incidence of fetal and neonatal adverse events-including intrauterine growth restriction, premature birth, intracranial haemorrhage, and fetal loss-in women with congenital heart disease compared with the general population (box 3). ${ }^{10}$ This risk is highest in women with poor functional class, cyanosis, and left heart obstruction to flow (which restricts cardiac output and thus flow to the placenta) and is amplified by any other obstetric risk factors. ${ }^{8-11}$

Doctors should emphasise the need to optimise both cardiac and general health of pregnant women

Extra references w1-w24 are on bmj.com

This article was posted on bmi.com on 13 February 2006: http://lbmj.com/cgi/doi/10.1136/bmj.38756.482882.DE
Adult Congenital Heart Disease Unit, Royal Brompton and Harefield NHS Trust and National Heart and Lung Institute at Imperial College, London SW3 6NP

Anselm Uebing fellow in adult congenital heart disease

Michael A Gatzoulis professor of cardiology, congenital heart disease

Academic

Department of

Obstetrics and

Gynaecology at

Chelsea and

Westminster

Hospital, Division

of Surgery,

Oncology,

Reproductive

Medicine and

Anaesthetics,

Faculty of Medicine,

Imperial College,

London

Philip J Steer

professor of obstetrics and gynaecology

Magill Department of Anaesthesia, Intensive Care and Pain Management, Chelsea and Westminster Hospital, London Steve M Yentis consultant anaesthetist

Correspondence to: M A Gatzoulis m.gatzoulis@rbh. nthames.nhs.uk

BMJ 2006;332:401-6 
Box 1: Counselling of women of reproductive age with congenital heart disease

Women should be given information on

- Maternal and fetal morbidity and mortality associated with pregnancy

- Risk of recurrence of congenital heart disease in the offspring

- Maternal (and paternal, when the partner has congenital heart disease) life expectancy

- Level of surveillance, need for treatment, and anticipated hospitalisation required during pregnancy

- Contraception

Box 2: Generic risk factors for women with congenital heart disease during pregnancy

- Poor functional class before pregnancy (New York Heart Association functional classification $>$ II) or cyanosis

- Impaired systemic ventricular function (ejection fraction $<40 \%$ )

- Left heart obstruction (mitral valve area $<2 \mathrm{~cm}^{2}$, aortic valve area $<1.5$ $\mathrm{cm}^{2}$, left ventricular outflow tract peak blood pressure gradient (measured by Doppler ultrasonography) $>30 \mathrm{~mm} \mathrm{Hg}$ before pregnancy)

- Preconception history of adverse cardiac events such as symptomatic arrhythmia, stroke, transient ischaemic attack, and pulmonary oedema ${ }^{89}$ The expected cardiac event rate in pregnancies with 0,1 , or $>1$ of these risk factors is $5 \%, 27 \%$, and $75 \%$, respectively ${ }^{9}{ }^{\mathrm{w} 1}$

Box 3: Generic risk factors for fetus of women with congenital heart disease

- Poor maternal functional class before pregnancy (New York Heart Association functional classification $>$ II) or maternal cyanosis

- Left heart obstruction (mitral valve area $<2 \mathrm{~cm}^{2}$, aortic valve area $<1.5$ $\mathrm{cm}^{2}$, left ventricular outflow tract peak blood pressure gradient $>30 \mathrm{~mm}$

$\mathrm{Hg}$ before pregnancy)

- Maternal age $<20$ or $>35$ years

- Maternal smoking

- Treatment with anticoagulants

with heart disease. For women with good cardiovascular function without cyanosis, routine surveillance of fetal growth should suffice. If clinical growth is unsatisfactory, growth should be checked with ultrasound biometry. For women with cyanotic or stenotic lesions, however, routine ultrasound biometry is justified. Close assessment of fetal growth is also advisable in patients with systemic hypertension or taking $\beta$ blockers. ${ }^{12}$

The risk of congenital heart disease in offspring

For pregnant women with congenital heart disease, the risk of their fetus having structural cardiac defects varies between about $3 \%$ and $12 \%$, compared with a background risk of $0.8 \%$ for the general population (see table 2). ${ }^{13}$ Specialised cardiac ultrasound screening should therefore be offered. A fetal nuchal translucency measurement at 12-13 weeks' gestation is a useful first screening test (the incidence of congenital heart disease is only $1 / 1000$ with normal nuchal thickness). ${ }^{14}$ For mothers with a strong family history of congenital heart disease, a specialist fetal cardiac echo scan at 14-16 weeks' gestation should be offered to detect moderate to severe congenital heart lesions, and this may need repeating at 18-22 weeks.
Maternal (or paternal if the father has congenital heart disease) life expectancy

Parental life expectancy should be discussed, as premature death, disability, or the need for major surgery will obviously affect a couple's ability to care for their child. The best available information should be given so that the couple can make an informed choice, bearing in mind potential improvements in prognosis with advances in cardiology. Fortunately, life expectancy is excellent for most patients with congenital heart disease, depending on their type of defect, previous interventions, and current haemodynamic status.

\section{Contraception and termination of pregnancy}

Congenital heart disease is no bar to sexual activities. ${ }^{\text {w2 }}$ Therefore, timely contraceptive counselling must be part of women's healthcare plan to avoid unplanned pregnancies and the need for termination (box 4).

\section{Care during pregnancy}

\section{Antenatal care}

The level of antenatal care and monitoring required should be determined before pregnancy, or when this is not possible as soon as pregnancy is confirmed. As many general obstetricians will see only a few patients with moderate to severe congenital heart disease, referral to a specialist centre for counselling is advisable. Low risk patients (table 1) can then continue with their
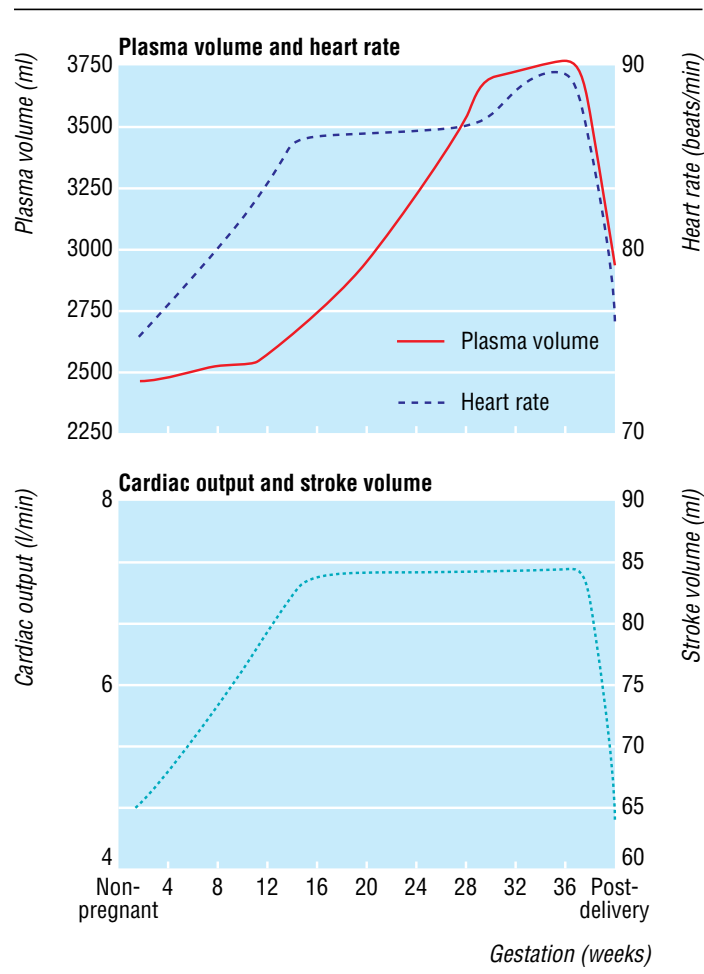

Fig 1 Cardiovascular changes during pregnancy (adapted from Thorne $^{5}$ with permission). Plasma volume and cardiac output increase steadily until the end of the second trimester, when cardiac output reaches a plateau at $30-50 \%$ above pre-pregnancy levels. Obstructive heart lesions (such as aortic or mitral valve stenosis), which limit cardiac output, are particularly compromised during pregnancy. The increase in blood volume may precipitate heart failure. Cyanosis often worsens during pregnancy as pregnancy related systemic vasodilation may lead to increased right to left shunting. 
antenatal care locally, taking into consideration the specialist recommendations.

Moderate to high risk patients should ideally be cared for in a tertiary, multidisciplinary environment where a 24 hour service of experienced obstetricians, anaesthetists, cardiologists, cardiac surgeons, and neonatologists can be provided. Careful planning for antenatal care and delivery is needed. The patient herself should be part of the decision making and understand the "minimal risk approach." Some patients may benefit from hospitalisation during the third trimester of pregnancy for bed rest, closer cardiovascular monitoring, and (for cyanotic patients) oxygen therapy. Patients admitted for bed rest should receive appropriate thromboprophylaxis with low molecular weight heparin.

Patients with Eisenmenger syndrome (or other forms of pulmonary arterial hypertension), Marfan syndrome with aortic root diameter $>4 \mathrm{~cm}$, or severe left side obstructive lesions should be told of the high maternal morbidity and mortality associated with pregnancy. If an unplanned pregnancy occurs, early termination should be considered. If the patient chooses to proceed with pregnancy, however, the need for care in a tertiary, multidisciplinary unit cannot be overemphasised.

\section{Anticoagulation}

Women with congenital heart disease often require anticoagulation to avoid thromboembolic events secondary to chronic or recurrent arrhythmia, sluggish blood flow (as present after Fontan-type palliative procedures), or metallic heart valve prostheses. The risk of thromboembolism is increased sixfold during pregnancy and 11-fold in the puerperium; thus adequate anticoagulation is vital. However, this poses substantial problems for both mother and fetus. Warfarin, an effective oral antico-

Table 1 Pregnancy related risks for women with congenital heart disease by specific lesion

\begin{tabular}{|c|c|c|c|}
\hline Lesion & Exclude before pregnancy & Potential hazards & Recommended treatment during pregnancy and peripartum \\
\hline \multicolumn{4}{|l|}{ Low risk lesions } \\
\hline Ventricular septal defects ${ }^{9}$ w8 w9 & Pulmonary arterial hypertension & $\begin{array}{l}\text { Arrhythmias } \\
\text { Endocarditis (unoperated or residual } \\
\text { defect) }\end{array}$ & Antibiotic prophylaxis for unoperated or residual defect \\
\hline $\begin{array}{l}\text { Atrial septal defects } \\
\text { (unoperated) }^{9} \text { w8 w } 9\end{array}$ & $\begin{array}{l}\text { Pulmonary arterial hypertension } \\
\text { Ventricular dysfunction }\end{array}$ & $\begin{array}{l}\text { Arrhythmias } \\
\text { Thromboembolic events }\end{array}$ & $\begin{array}{l}\text { Thromboprophylaxis if bed rest is required } \\
\text { Consider low dose aspirin during pregnancy }\end{array}$ \\
\hline Coarctation (repaired) $)^{w 10}$ & $\begin{array}{l}\text { Recoarctation } \\
\text { Aneurysm formation at side of repair (MRI) } \\
\text { Associated lesion such as bicuspid aortic valve } \\
\text { (with or without aortic stenosis or aortic } \\
\text { regurgitation), ascending aortopathy } \\
\text { Systemic hypertension } \\
\text { Ventricular dysfunction }\end{array}$ & $\begin{array}{l}\text { Pre-eclampsia (coarctation is the only } \\
\text { congenital heart lesion known as an } \\
\text { independent predictor of pre-eclampsia) } \\
\text { Aortic dissection } \\
\text { Congestive heart failure } \\
\text { Endarteritis }\end{array}$ & $\begin{array}{l}\beta \text { Blockers if necessary to control systemic blood pressure } \\
\text { Consider elective caesarean section before term in case of } \\
\text { aortic aneurysm formation or uncontrollable systemic } \\
\text { hypertension } \\
\text { Antibiotic prophylaxis }\end{array}$ \\
\hline Tetralogy of Fallotw1 w12 & $\begin{array}{l}\text { Severe right ventricular outflow tract obstruction } \\
\text { Severe pulmonary regurgitation } \\
\text { Right ventricular dysfunction } \\
\text { DiGeorge syndrome }\end{array}$ & $\begin{array}{l}\text { Arrhythmias } \\
\text { Right ventricular failure } \\
\text { Endocarditis }\end{array}$ & $\begin{array}{l}\text { Consider preterm delivery in the rare case of right ventricular } \\
\text { failure } \\
\text { Antibiotic prophylaxis }\end{array}$ \\
\hline \multicolumn{4}{|l|}{ Moderate risk lesions } \\
\hline Mitral stenosis ${ }^{\mathrm{w8}}$ & $\begin{array}{l}\text { Severe stenosis } \\
\text { Pulmonary venous hypertension }\end{array}$ & $\begin{array}{l}\text { Atrial fibrillation } \\
\text { Thromboembolic events } \\
\text { Pulmonary oedema }\end{array}$ & $\begin{array}{l}\beta \text { Blockers } \\
\text { Low dose aspirin } \\
\text { Consider bed rest during third trimester with additional } \\
\text { thromboprophylaxis } \\
\text { Antibiotic prophylaxis }\end{array}$ \\
\hline Aortic stenosis ${ }^{\mathrm{w} 13 \mathrm{w} 14}$ & $\begin{array}{l}\text { Severe stenosis (peak pressure gradient on } \\
\text { Doppler ultrasonography }>80 \mathrm{~mm} \mathrm{Hg} \text {, ST segment } \\
\text { depression, symptoms) } \\
\text { Left ventricular dysfunction }\end{array}$ & $\begin{array}{l}\text { Arrhythmias } \\
\text { Angina } \\
\text { Endocarditis } \\
\text { Left ventricular failure }\end{array}$ & $\begin{array}{l}\text { Bed rest during third trimester with thromboprophylaxis } \\
\text { Consider balloon aortic valvotomy (for severe symptomatic } \\
\text { valvar stenosis) or preterm caesarean section if cardiac } \\
\text { decompensation ensues (bypass surgery carries } 20 \% \text { risk of } \\
\text { fetal death) } \\
\text { Antibiotic prophylaxis }\end{array}$ \\
\hline $\begin{array}{l}\text { Systemic right ventricle (TGA } \\
\text { after atrial switch procedure, } \\
\text { ccTGA) }\end{array}$ & $\begin{array}{l}\text { Ventricular dysfunction } \\
\text { Severe systemic atrioventricular valve regurgitation } \\
\text { Bradyarrhythmias and tachyarrhythmias } \\
\text { Heart failure (NHYA >II) } \\
\text { Obstruction of venous pathways after atrial switch } \\
\text { as venous blood flow significantly increases during } \\
\text { pregnancy }\end{array}$ & $\begin{array}{l}\text { Right ventricular dysfunction (potentially } \\
\text { persisting after pregnancy) } \\
\text { Heart failure } \\
\text { Arrhythmias } \\
\text { Thromboembolic events } \\
\text { Endocarditis }\end{array}$ & $\begin{array}{l}\text { Regular monitoring of heart rhythm } \\
\text { Restore sinus rhythm in case of atrial flutter (cardioversion } \\
\text { usually effective and safe) } \\
\text { Alter afterload reduction therapy (stop ACE inhibitors; } \\
\text { consider } \beta \text { blockers) } \\
\text { Low dose aspirin }(75 \mathrm{mg} \text { ) } \\
\text { Antibiotic prophylaxis }\end{array}$ \\
\hline $\begin{array}{l}\text { Cyanotic lesions without } \\
\text { pulmonary hypertension }^{11}\end{array}$ & Ventricular dysfunction & $\begin{array}{l}\text { Haemorrhage (bleeding diathesis) } \\
\text { Thromboembolic events } \\
\text { Increased cyanosis } \\
\text { Heart failure } \\
\text { Endocarditis }\end{array}$ & $\begin{array}{l}\text { Consider bed rest and oxygen supplementation to maintain } \\
\text { oxygen saturation and promote oxygen tissue delivery } \\
\text { (thromboprophylaxis with low molecular weight heparin) } \\
\text { Antibiotic prophylaxis }\end{array}$ \\
\hline Fontan-type circulation ${ }^{\text {w19 }}$ & $\begin{array}{l}\text { Ventricular dysfunction } \\
\text { Arrhythmias } \\
\text { Heart failure (NYHA >II) }\end{array}$ & $\begin{array}{l}\text { Heart failure } \\
\text { Arrhythmias } \\
\text { Thromboembolic complications } \\
\text { Endocarditis }\end{array}$ & $\begin{array}{l}\text { Consider anticoagulation with low molecular weight heparin } \\
\text { and aspirin throughout pregnancy } \\
\text { Maintain sufficient filling pressures and avoid dehydration } \\
\text { during delivery } \\
\text { Antibiotic prophylaxis }\end{array}$ \\
\hline \multicolumn{4}{|l|}{ High risk lesions } \\
\hline Marfan syndrome ${ }^{w 20}$ & Aortic root dilatation $>4 \mathrm{~cm}$ & Type $A$ dissection of aorta & $\begin{array}{l}\beta \text { Blockers in all patients } \\
\text { Elective caesarean section when aortic root }>45 \mathrm{~mm}(\sim 35 \\
\text { weeks' gestation) }\end{array}$ \\
\hline 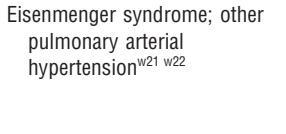 & $\begin{array}{l}\text { Ventricular dysfunction } \\
\text { Arrhythmias }\end{array}$ & $\begin{array}{l}30-50 \% \text { risk of death related to } \\
\text { pregnancy } \\
\text { Arrhythmia } \\
\text { Heart failure } \\
\text { Endocarditis for Eisenmenger syndrome }\end{array}$ & $\begin{array}{l}\text { Therapeutic termination should be offered } \\
\text { If pregnancy continues, close cardiovascular monitoring, } \\
\text { early bed rest, pulmonary vasodilator therapy with } \\
\text { supplemental oxygen should be considered } \\
\text { Close monitoring necessary for } 10 \text { days postpartum }\end{array}$ \\
\hline
\end{tabular}

MRI=magnetic resonance imaging, NYHA=New York Heart Association functional classification, TGA=transposition of the great arteries, ccTGA=congenitally corrected TGA 


\section{Box 4: Contraception and termination of pregnancy for women} with congenital heart disease

\section{Contraception}

None of the methods available today is optimal for women with congenital heart disease

- "Natural methods" (abstinence, withdrawal, safe period) and "barrier methods" (condoms, diaphragm) have unacceptably high failure rates and cannot be recommended for women in whom pregnancy carries a substantial risk

- Combined oral contraceptives should be avoided in patients at risk of thromboembolism (cyanosis impaired cardiac function, atrial arrhythmias, Fontan-type circulation, and prosthetic heart valves) because of the thrombophilic properties of oestrogen

- Progestogen-only oral contraceptives (the "mini pill") do not increase the risk for thromboembolism and have few serious side effects (such as irregular uterine bleeding), but the failure rate is higher than that of the combined pill. Depot injections of progestogen are an alternative to the mini pill, especially for adolescents for whom compliance is a concern - An intrauterine device impregnated with progestogen has been an important advance in contraception for patients with high risk for pregnancy related complications and thromboembolism. Such devices are highly effective and safe: they reduce menstrual bleeding and carry a very low risk of infection and ectopic pregnancy

- Sterilisation should be considered for women in whom pregnancy would carry a prohibitively high risk or when a couple decide that they never want to have children. Sterilisation is permanent, although there is still a 1/200 pregnancy rate, and there are surgical risks associated with the procedure

\section{Termination of pregnancy}

- The risk of termination of pregnancy increases with increasing gestational age and should be performed as soon as the decision has been made, preferably in the first trimester

- Suction curettage under local anaesthesia is the preferred method

- Medical abortion with oral antiprogesterones and vaginally administered prostaglandins is probably contraindicated because the haemodynamic effects (systemic vasodilation with hypotension, increasing cyanosis, heavy bleeding, retention of products with infection) are unpredictable

agulant, crosses the placenta and thus carries major risks for the fetus (fig 2). ${ }^{15} 16$ w3 In contrast, heparin does not cross the placenta and is therefore safe for the fetus. However, it is reported to be less effective for thromboprophylaxis, particularly in women with metallic valve prostheses. ${ }^{17} 18$ Therefore, any advice on anticoagulant treatment during pregnancy must weigh the risks and benefits for both mother and fetus, and decisions regarding treatment should be made jointly with the patient and her partner.

Table 2 Risk of recurrent disease in offspring of parents with congenital heart disease

\begin{tabular}{lcccccc} 
& \multicolumn{2}{c}{ Mother affected } & & \multicolumn{2}{c}{ Father affected } \\
\cline { 2 - 3 } Lesion & $\begin{array}{c}\text { Risk of transmission } \\
\mathbf{( \% )}\end{array}$ & $\begin{array}{c}\text { No of } \\
\text { cases }\end{array}$ & & $\begin{array}{c}\text { Risk of transmission } \\
\mathbf{( \% )}\end{array}$ & $\begin{array}{c}\text { No of } \\
\text { cases }\end{array}$ \\
\hline Atrioventricular septal defect & 11.6 & $5 / 43$ & & 4.3 & $1 / 23$ \\
\hline Aortic stenosis & 8.0 & $36 / 248$ & & 3.8 & $18 / 469$ \\
\hline Coarctation & 6.3 & $14 / 222$ & & 3.0 & $9 / 299$ \\
\hline Atrial septal defect & 6.1 & $59 / 969$ & & 3.5 & $16 / 451$ \\
\hline Ventricular septal defect & 6.0 & $44 / 731$ & & 3.6 & $26 / 717$ \\
\hline Pulmonary stenosis & 5.3 & $24 / 453$ & & 3.5 & $14 / 396$ \\
\hline Persistent ductus arteriosus & 4.1 & $39 / 828$ & & 2.0 & $5 / 245$ \\
\hline Tetralogy of Fallot & 2.0 & $6 / 301$ & & 1.4 & $5 / 362$ \\
\hline Total & 5.8 & $222 / 3795$ & & 3.1 & $93 / 2961$ \\
\hline
\end{tabular}

Data from Nora $1994,{ }^{13}$ a meta-analysis of 13 studies undertaken between 1969 and 1994 . Recurrence risk largely depends on the type of the lesion, the sex of the parent affected, and the family history of congenital

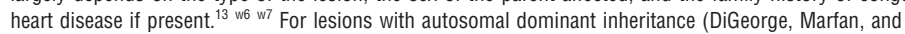
Noonan's syndromes), the risk for recurrence of congenital heart disease can be as high as $50 \%$.
Ideally, women of reproductive age with valvular heart disease who are undergoing surgery should have tissue rather than metallic prostheses to avoid the need for anticoagulation during future pregnancies. Anticoagulation has implications for analgesic or anaesthetic options for delivery, since epidural or spinal techniques may carry a risk of intraspinal bleeding depending on the dose and timing of anticoagulant treatment.

\section{Cardiac drugs in pregnancy}

Most commonly used cardiovascular drugs for patients with heart disease cross the placenta and expose the fetus to their pharmacological effects. Some drugs also enter breast milk and may affect the neonate and infant. Although many drugs routinely used in pregnancy are relatively safe, the benefits and risks for mother and fetus have to be weighted carefully (box 5). ${ }^{21} 22 \mathrm{w4}$

\section{Delivery and the postpartum period}

Labour and delivery must be planned carefully and well in advance. Ideally, decisions about timing and mode of delivery should be agreed after a multidisciplinary case discussion including the patient. These decisions must be communicated appropriately to the patient and to the tertiary and local healthcare teams. In our practice, we copy the notes, all investigations, and the recommended delivery plan to the patient.

\section{Box 5: Safety profiles of cardiac drugs in pregnancy}

The lowest possible effective dose should be used, and a single drug regimen should be aimed for. For more detail see references ${ }^{2122 w 4}$

\section{Relatively safe}

- Adenosine

- Amiloride

- $\beta$ Blockers-Close monitoring is essential, however, because they may affect fetal growth and may blunt the fetal heart rate response under hypoxic conditions - Calcium channel blockers

- Digoxin

- Flecainide

- Heparin

- Lidocaine

- Mexiletine

- Procainamide

- Quinidine

Not safe

- Angiotensin converting enzyme inhibitors, angiotensin-II receptor antagonists-Risk of neonatal renal failure and hypotension, renal tubular dysgenesis, intrauterine growth restriction, decreased skull ossification

- Warfarin-Risk of skeletal defects, abnormalities of the central nervous system, intracranial haemorrhage - Amiodarone-May be used in special circumstances, but risk of hypothyroidism and potential brain damage

- Phenytoin-Risk of heart defects, intrauterine growth restriction, orofacial abnormalities

- Spironolactone-Possible risk of anomalies of the external genitalia (animal studies only). If potassium sparing diuretics are needed, amiloride is preferable 
In principle, vaginal delivery carries a lower risk of complications for both the mother and the fetus. Compared with caesarean section, it causes smaller shifts in blood volume, less haemorrhage, fewer clotting complications, and fewer infections. ${ }^{23}$ However, prolonged and difficult labour should be avoided, and detailed continuous monitoring of the mother and fetus is mandatory.

The principle is to manage the stress of labour in such a way that it does not exceed the woman's capacity to cope with it. In this regard, early epidural analgesia with a cardiostable drug at low dose is important. Good regional analgesia helps to avoid further increases in cardiac output associated with contractions and allows instrumental delivery or careful extension should anaesthesia for caesarean section be required..$^{24}$ Labour should not be induced unless for obstetric indications or because of developing cardiovascular compromise. Spontaneous labour is usually quicker and carries a higher chance of a successful delivery than induced labour. The threshold for assisted delivery either by vacuum extraction or forceps should be low in order to avoid a prolonged second stage of labour. ${ }^{23}$

Maternal monitoring during labour should be individualised and usually includes continuous electrocardiographic monitoring and pulse oximetry, and occasionally invasive blood pressure recording. All women with congenital heart disease should be warned against lying flat during pregnancy, and especially labour, to avoid aortocaval compression (left decubitus position is the position of choice). Endocarditis prophylaxis should be considered for most patients with congenital heart disease irrespective of the mode of delivery.

The early postpartum period is also potentially dangerous. With uterine contraction, there is transfusion of extra blood into the circulation, which can cause volume overload. Conversely, there is a risk of uterine haemorrhage with substantial loss of blood volume, potentially leading to haemodynamic compromise. Oxytocic drugs such as oxytocin and ergometrine that improve uterine contraction have also major haemodynamic effects. Oxytocin can induce vasodilatation and arterial hypotension, and ergometrine can cause arterial hypertension. These adverse cardiovascular effects may be catastrophic if the drugs are given rapidly or in high dose (any oxytocic drug should be given as a continuous infusion at the lowest effective rate). Preparations containing a combination of oxytocin and ergometrine have unpredictable effects on the circulatory system and should be avoided. ${ }^{25}$ Management of the early postpartum period should aim to avoid fluctuations in blood volume and blood pressure as much as possible..$^{2325}$

Ongoing monitoring is necessary in high risk patients during the puerperium. This is particularly so for patients with pulmonary arterial hypertension, where the risk of maternal death remains high for up to 10 days. ${ }^{\text {w5 }}$ Thromboprophylaxis with low molecular weight heparin is of major importance before and after delivery and should continue until the mother is fully mobilised. Warfarin is safe during breast feeding and can be reinstated 6-12 hours after delivery.

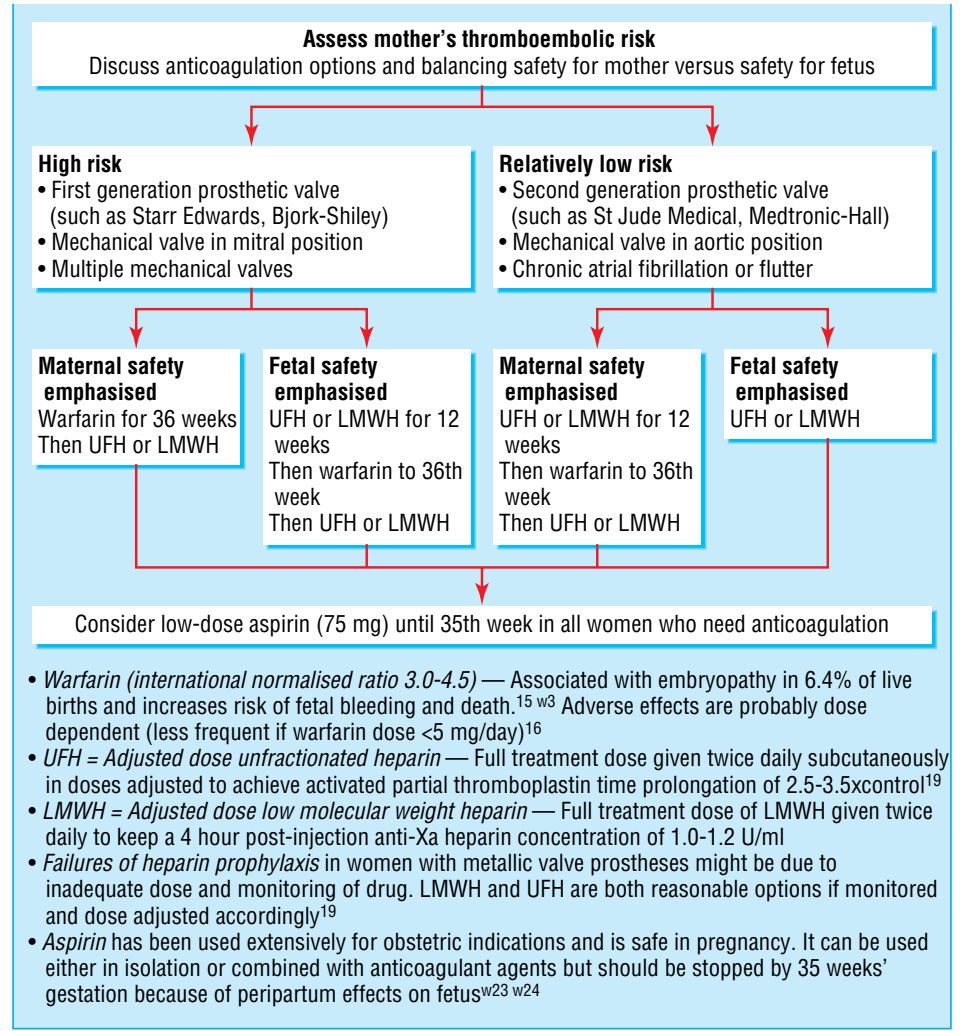

Fig 2 Proposed algorithm for anticoagulation therapy during pregnancy for women with congenital heart disease (modified from Elkayam ${ }^{20}$ )

\section{Summary}

Although pregnancy can pose substantial risks for women with congenital heart disease, it remains feasible for most with suitable medical support. Pre-pregnancy counselling and multidisciplinary care including cardiologists, obstetricians, and anaesthetists are essential to help these women have their own children at the minimal possible risk and, thus, allow them to reach their full life potential.

Competing interests: None declared.

1 Nieminen HP, Jokinen EV, Sairanen HI. Late results of pediatric cardiac surgery in Finland: a population-based study with $96 \%$ follow-up. Circulation 2001;104:570-5.

2 Thorne S, Deanfield J. Long-term outlook in treated congenital heart disease. Arch Dis Child 1996;75:6-8.

3 Wren C, O'Sullivan IJ. Survival with congenital heart disease and need for follow up in adult life. Heart 2001;85:438-43.

4 Lewis G, Drife JO. Why mothers die 2000-2002-The sixth report of confidential enquiries into maternal deaths in the United Kingdom. London: RCOG Press, 2004.

5 Thorne SA. Pregnancy in heart disease. Heart 2004;90:450-6.

6 Task Force on the Management of Cardiovascular Diseases During Pregnancy of the European Society of Cardiology. Expert consensus document on management of cardiovascular diseases during pregnancy. Eur Heart J 2003;24:761-81.

\section{Additional educational resources}

Grown Up Congenital Heart (GUCH) Patients Association (www.guch.org.uk)-Offers valuable information for patients regarding pregnancy and other issues relevant to congenital heart disease

ISACCD, International Society for Adult Congenital Cardiac Disease (www.isaccd.org)-Offers useful information for professionals and patients alike and provides relevant links to other websites

Canadian Adult Congenital Heart Network (www.cachnet.org)-Gives detailed information about the management of patients with congenital heart disease and risks related to pregnancy 
7 Gatzoulis MA. Adult congenital heart disease: education, education, education. Nat Clin Pract Cardiouasc Med 2006:3:2-3.

Siu SC, Sermer M, Harrison DA Grigoriadis E, Liu G, Sorensen S, et al. Risk and predictors for pregnancy-related complications in women with heart disease. Circulation 1997;96:2789-94.

9 Siu SC, Sermer M, Colman JM, Alvarez AN, Mercier LA, Morton BC, et al Prospective multicenter study of pregnancy outcomes in women with heart disease. Circulation 2001;104:515-21

10 Siu SC, Colman JM, Sorensen S, Smallhorn JF, Farine D, Amankwah KS, et al. Adverse neonatal and cardiac outcomes are more common in pregnant women with cardiac disease. Circulation 2002;105:2179-84.

11 Presbitero P, Somerville J, Stone S, Aruta E, Spiegelhalter D, Rabajoli F. Pregnancy in cyanotic congenital heart disease. Outcome of mother and fetus. Circulation 1994;89:2673-6.

12 Easterling TR, Carr DB, Brateng D, Diederichs C, Schmucker B. Treatment of hypertension in pregnancy: effect of atenolol on maternal disease, preterm delivery, and fetal growth. Obstet Gynecol 2001;98:427-33.

13 Nora JJ. From generational studies to a multilevel genetic-environmental interaction. J Am Coll Cardiol 1994;23:1468-71.

14 Hyett J, Perdu M, Sharland G, Snijders R, Nicolaides KH. Using fetal nuchal translucency to screen for major congenital cardiac defects at 10-14 weeks of gestation: population based cohort study. BMJ 1999;318:81-5

15 Chan WS, Anand S, Ginsberg JS. Anticoagulation of pregnant women with mechanical heart valves: a systematic review of the literature. Arch Intern Med 2000;160:191-6.

16 Vitale N, De Feo M, De Santo LS, Pollice A, Tedesco N, Cotrufo M. Dosedependent fetal complications of warfarin in pregnant women with mechanical heart valves. J Am Coll Cardiol 1999;33:1637-41.
17 Roberts N, Ross D, Flint SK, Arya R, Blott M. Thromboembolism in pregnant women with mechanical prosthetic heart valves anticoagulated with low molecular weight heparin. BJOG 2001;108:327-9.

18 Ellison J, Thomson AJ, Walker ID, Greer IA. Use of enoxaparin in a pregnant woman with a mechanical heart valve prosthesis. BJOG 2001;108:757-9.

19 Bates SM, Greer IA, Hirsh J, Ginsberg JS. Use of antithrombotic agents during pregnancy: the Seventh ACCP Conference on Antithrombotic and Thrombolytic Therapy. Chest 2004;126(3 suppl):627-44S

20 Elkayam U. Pregnancy through a prosthetic heart valve.J Am Coll Cardiol 1999;33:1642-5.

21 Qasqas SA, McPherson C, Frishman WH, Elkayam U. Cardiovascular pharmacotherapeutic considerations during pregnancy and lactation. Cardiol Rev 2004:12:201-21.

22 Qasqas SA, McPherson C, Frishman WH, Elkayam U. Cardiovascular pharmacotherapeutic considerations during pregnancy and lactation. Cardiol Rev 2004;12:240-61.

23 Steer PJ. Pregnancy and contraception. In: Gatzoulis MA, Swan L, Therrien J, Pantely GA, eds. Adult congenital heart disease: A practical guide. Oxford: BMJ Publishing, Blackwell Publishing, 2005:16-35.

24 Suntharalingam G, Dob D, Yentis SM. Obstetric epidural analgesia in aortic stenosis: a low-dose technique for labour and instrumental delivery. Int J Obstet Anesth 2001;10:129-34.

25 Lupton M, Oteng-Ntim E, Ayida G, Steer PJ. Cardiac disease in pregnancy. Curr Opin Obstet Gynecol 2002;14:137-43.

\title{
Interactive case report
}

\section{A 28 year old postpartum woman with right sided chest discomfort: case presentation}

\author{
Girish Dwivedi, Sajad Ahmed Hayat, Andonis G Violaris, Roxy Senior
}

Department of Cardiovascular Medicine, Northwick Park Hospital, Harrow, Middlesex, HA1 3UJ

Girish Dwivedi registrar in cardiology Sajad Ahmed Hayat registrar in cardiology Andonis G Violaris consultant cardiologist Roxy Senior consultant cardiologist Correspondence to: R Senior

roxy.senior@virgin.net

BMJ 2006;332:406
Mrs Patel, a 28 year old woman with a 7 month old baby, presented to the accident and emergency department with a severe episode of right sided chest pain. The pain, which had started two months ago, was well localised over the right chest wall with no radiation. However, it was precipitated by exertion, particularly while pushing her daughter's pushchair and was limiting her recreational activities with her child. The pain was not exacerbated by deep inspiration, coughing, or twisting, and she had no associated symptoms of dyspnoea, palpitations, or dizziness. She had consulted her general practitioner and was being treated for a presumed musculoskeletal condition.

Her coronary artery disease risk factors included diabetes mellitus, diagnosed three years ago, which was well controlled with oral treatment (glycated haemoglobin 7.5\%). She also had hypothyroidism and was taking $25 \mu \mathrm{g}$ levothyroxine daily. She had never smoked and had no history of hypertension; her lipid status was unknown.

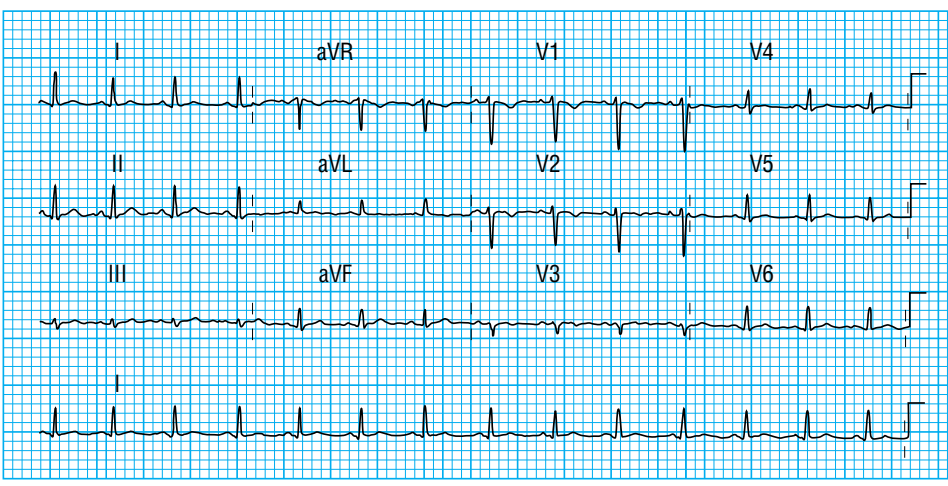

Mrs Patel's resting electrocardiogram

\section{Questions}

1 What would be your initial management of Mrs Patel?

2 What further investigations would you suggest?

3 What would you tell Mrs Patel and her family at this stage?

Please respond through bmj.com, remembering that Mrs Patel is a real patient and that she and her carers will be reading the responses

She was obese (body mass index 34.6) but otherwise in good health. Her pulse was 70 beats per minute and regular and her blood pressure was 130/70 mm Hg. All peripheral pulses were palpable with no audible bruits. She had normal heart sounds with no murmurs, and her chest was clear with no adventitious sounds. There were no breast lumps or tenderness. Abdominal examination found no abnormality. Her resting electrocardiogram showed sinus rhythm with poor $\mathrm{R}$ wave progression in the anterior leads. Inverted and biphasic T waves were noted in leads V2 and V3 (figure).

Competing interests: None declared.

This is the first of a three part case report where we invite readers to take part in considering the diagnosis and management of a case using the rapid response feature on bmj.com. Next week we will report the case progression and in four weeks' time we will report the outcome and summarise the responses 